\title{
Health Insurance and Tax Policy *
}

\author{
Karsten Jeske ${ }^{\dagger}$ \\ Sagiri Kitao ${ }^{\ddagger}$
}

November 6, 2006

\begin{abstract}
The U.S. tax policy on health insurance favors only those offered group insurance through their employers, and is regressive since the subsidy takes the form of deductions from the progressive income tax system. The paper investigates alternatives to the current policy within a framework of a dynamic general equilibrium model. We find that despite the issues about the current policy, a complete removal of the subsidy results in a partial collapse of the group insurance market and a significant reduction in the insurance coverage, negatively affecting the welfare of many. There is, however, room for raising the coverage and significantly improving welfare by extending refundable credits to the individual insurance market. Our work is the first in highlighting the importance of studying the tax policy associated with health insurance in a general equilibrium framework with an endogenous demand for the insurance. We use the Medical Expenditure Panel Survey (MEPS) to calibrate the process for income, health expenditure shocks and health insurance offer status through employers and succeed in producing the pattern of insurance demand as observed in the data, which serves as a solid benchmark for the policy experiments.
\end{abstract}

JEL codes: E21, E62, I10

Keywords: health insurance, risk sharing, tax policy

*The authors thank Thomas Sargent, Gianluca Violante, James Nason and seminar participants at the Federal Reserve Bank of Atlanta, German Macro Workshop, New York University, the 2006 SED meetings and University of Southern California for helpful comments, and Katie Hsieh for research assistance. All remaining errors are ours. Moreover, the views expressed here are not necessarily those of the Federal Reserve Bank of Atlanta or the Federal Reserve System. The authors can be reached at Karsten.Jeske@atl.frb.org and sagiri.kitao@nyu.edu.

${ }^{\dagger}$ Federal Reserve Bank of Atlanta

$\ddagger$ New York University 


\section{Introduction}

The aim of this paper is to study the effects of tax policy on the health insurance decision of households in a general equilibrium framework with heterogenous agents. We motivate the economic importance of health care and health insurance by noting that in absolute and relative terms Americans spend a sizeable amount of resources on health care. According to the Bureau of Economic Analysis (BEA), medical care expenditures account for $12.0 \%$ of GDP in 2005, more than housing services $(10.5 \%)$, food $(9.7 \%)$ or durable goods consumption $(8.3 \%)$. In absolute terms, an average American spends more than $\$ 5,000$ on health care. At the same time a record number of 46 million people or $16 \%$ of the population lack health insurance.

Not surprisingly, the U.S. government is involved in the health insurance market through government-run medical programs and the tax policy. In 2004, Medicare and Medicaid combined spent $\$ 560$ billion, almost 5\% of GDP. A lesser-known health policy is the estimated $\$ 133$ billion a year subsidy the government provides in the form of tax-deductibility of employer-provided health insurance. ${ }^{1}$ The origin of this policy lies in the price and wage controls the federal government imposed during the World War II. Companies used the employer-provided health benefits as a non-price mechanism to compete for workers that were in short supply, thereby circumventing the wage controls. Subsequent to lifting the price and wage controls, employers kept providing health plans because they could be financed with pre-tax income. The tax deductibility was extended to health insurance premiums of self-employed individuals in 1986.

The classic work of Bewley (1986), Imrohoroglu (1992), Huggett (1993) and Aiyagari (1994) has created a large literature studying uninsurable labor productivity risk. Many recent papers investigated issues such as risk-sharing among agents, wealth and consumption inequality and welfare consequences of market incompleteness. ${ }^{2}$ We contribute to this literature by setting up a model in the tradition of Aiyagari (1994) but add idiosyncratic health expenditure risk which is partially insurable according to the endogenous insurance decisions.

Health expenditure shocks have been found to be helpful in adding realism to Aiyagari-type models. For example, according to Livshits, MacGee and Tertilt (2006) and Chatterjee, Corbae,

\footnotetext{
${ }^{1}$ Figures from Office of Management and Budget (Medicare and tax-cost of employer provided insurance) and U.S. Health and Human Services (Medicaid).

${ }^{2}$ See for example Fernandez-Villaverde and Krueger (2004) and Krueger and Perri (2005).
} 
Nakajima and Rios-Rull (2005), health expenditure shocks are an important source of consumer bankruptcies. Hubbard, Skinner, and Zeldes (1995) add a health expenditure shock to Aiyagari's model and argue that the social safety net discourages savings by low income households. Only high income households accumulate precautionary savings to shield themselves from catastrophic health expenditures. Palumbo (1999) and De Nardi, French and Jones (2005) incorporate into a model heterogeneity in medical expenses in order to understand the pattern of savings among the elderly. What is common to papers in the existing macro-literature is that health insurance is absent from the model and consequently a household's out-of-pocket expenditure process is exogenous.

Kotlikoff (1989) builds an overlapping generations model where households face idiosyncratic health shocks and studies the effect of medical expenditures on precautionary savings. He considers different insurance schemes, such as self-payment, insurance, or Medicaid, which agents take as exogenously given. In our paper, we combine all three of them into one model and let households decide how they want to insure against health expenditure shocks.

Gruber (2004) measures the effects of different subsidy policies for non-group insurance on the fraction of uninsured by employing a micro-simulation model that relies on reduced-form decision rules for households.

Within our micro-founded framework, we conduct policy experiments based on optimized decision rules, which enables us to compare the welfare effect of policy experiments as well as the changes in the insurance coverage. Moreover, we can take into account important general equilibrium effects. For example, our model can evaluate the fiscal consequences of policy reforms. Expanding the subsidy may require a higher tax rate on other sources of income which can generate distortions in other sectors, or alter the demand for social welfare programs such as Medicaid. It is difficult to compute welfare consequences of these policy experiments without an optimizing model of the household. Changing the tax treatment of health insurance premiums will also affect agents' savings behavior (and thus the aggregate capital stock and factor prices) directly through marginal taxes as well as indirectly because the lack of health insurance drives the precautionary savings motives. In each policy experiment, we first compute a steady state outcome and then explicitly compute the transition dynamics between the calibrated benchmark and the new steady state implied by an alternative policy in order to accurately assess the welfare 
consequences on the current generations.

Our paper is also related to the literature on income taxation in incomplete markets with heterogeneous agents, particularly the macroeconomic implication and welfare and redistributional effects of alternative tax systems. ${ }^{3}$ A tax reform will generate a new path of factor prices, which affects heterogeneous agents in different ways.

This paper sets up an overlapping generation general equilibrium model to evaluate the merits of the tax-deductibility of health insurance. We investigate three main issues about the current U.S. tax policy on health insurance. First, we study what the current tax treatment of health insurance does in terms of health insurance coverage and investigate how it affects macroeconomic variables and welfare. Specifically, we determine whether completely abolishing the tax deductibility of employer-provided health insurance improves welfare. Second, a progressive income tax implies individuals facing a higher marginal income tax receive a larger tax break and thus creates vertical inequity across different income groups. We consider a policy that eliminates the regressiveness of the policy while preserving the benefits provided for the group insurance market. Third, since the tax benefits are limited to the group insurance market and fail to satisfy horizontal equity depending on the offer status of group insurance, we determine the effects of extending preferential tax treatment or providing subsidies to those not offered employer-provided health insurance. In order to better understand the consequences of the reform, in particular the welfare effects on the current generations, we explicitly compute the transition dynamics towards the new steady state upon the implementation of a reform.

Our quantitative analysis shows that completely removing the tax subsidy would substantially decrease the health insurance coverage and negatively affect welfare because of a partial collapse of the group insurance market. This is due to the healthy agents dropping out of the group insurance market as they are no longer willing to subsidize higher risk agents in the pool of group insurance contracts. Eliminating vertical inequality by removing the regressiveness of tax benefits will reduce the benefit of group insurance for the rich and increase the benefit for the poor. The insurance coverage will decrease as a result of the healthy and income rich agents deciding not to purchase a group insurance.

\footnotetext{
${ }^{3}$ See for example Domeij and Heathcote (2004), Castaneda, Diaz-Gimenez and Rios-Rull (2005), Conesa and Krueger (2006), Conesa, Kitao and Krueger (2006).
} 
To restore horizontal equity, there are many paths the government could take. Various reform proposals are being debated in the policy arena, such as extending the deductibility to the nongroup insurance market or providing a subsidy for any insurance purchase. We simulate such reforms and find they are effective in raising the insurance coverage and improving welfare.

The paper proceeds as follows. Section 2 introduces the model. Section 3 details the parameterizations of the model. Some parameters will be estimated within the model by matching moments from the data and others will be calibrated. Section 4 shows the numerical results of the computed model both from the benchmark and from policy experiments. Section 5 concludes.

\section{Model}

\subsection{Demographics}

We employ an overlapping generations model with stochastic aging and dying. The economy is populated by two generations of agents, the young and the old. The young agents supply labor and earn the wage income. Old agents are retired from market work and receive social security benefits. ${ }^{4}$ The young agents become "old" and retire with probability $\rho_{o}$ every period and old agents die with probability $\rho_{d}$. We will later calibrate the probabilities so as to match the current age structure of the two generations.

We assume the population remains constant. Old agents who die and leave the model are replaced by the entry of the same number of young agents. The initial assets of the entrants are assumed to be zero. This demographic transition pattern generates a fraction of $\frac{\rho_{d}}{\rho_{d}+\rho_{o}}$ of young people in each generation and a fraction of $\frac{\rho_{o}}{\rho_{d}+\rho_{o}}$ of old people. All bequests are accidental and they are collected by the government and transferred in a lump-sum manner.

\footnotetext{
${ }^{4}$ In the computation, we distinguish the old agents who just retired in the previous period from the rest of the old agents and call the former as "recently retired" agents and the latter as "old" agents. The distinction between the two old generations is necessary because recently retired agents have a different state space from the rest of the old agents as we discuss below.
} 


\subsection{Endowment}

Agents are endowed with a fixed amount of time and the young agents supply labor inelastically. Their labor income depends on an idiosyncratic stochastic component $z$ and the wage rate $w$, and it is given as $w z$. Productivity shock $z$ is drawn from a set $\mathbb{Z}=\left\{z_{1}, z_{2}, \ldots, z_{N_{z}}\right\}$ and follows a Markov process that evolves jointly with the probability of being offered employer-based health insurance, which we discuss in the next subsection. Newly born young agents make a draw from the unconditional distribution of this process.

\subsection{Health and health insurance}

In each period, agents face an idiosyncratic health expenditure shock $x$. Young agents have access to the health insurance market, where they can purchase a contract that covers a fraction $q(x)$ of the medical cost $x$. Therefore, with the health insurance contract, the net cost of restoring the health will be $(1-q(x)) x$, while it will cost the entire $x$ without insurance. Notice that we allow the insurance coverage rate $q$ to depend on the size of the medical bill $x$. As we discuss in the calibration section, $q$ increases in $x$ due to deductibles and copayments. Agents must decide whether to be covered by insurance before they discover their expenditure shock.

Agents can purchase health insurance either in the individual market or through their employers. We call a contract purchased in the first market as "individual health insurance (IHI)" as opposed to "group health insurance (GHI)" purchased in the workplace. While every agent has access to the individual market, group health insurance is available only if such a benefit plan is offered by the employer.

If a young agent decides to purchase group health insurance through his employer, a constant premium $p$ must be paid to an insurance company in the year of the coverage. The premium is not dependent on prior health history or any individual states. This accounts for the practice that group health insurance will not price-discriminate the insured by such individual characteristics. We also allow the employer to subsidize the premium. More precisely, if an agent works for a firm that offers employer-based health insurance benefits, a fraction $\psi \in[0,1]$ of the premium is paid by the employer, so the marginal cost of the contract faced by the agent is only $(1-\psi) p$. In the individual health insurance market, we assume that the premium is $p_{m}(x)$, that is, the 
premium depends on the current health expenditure state $x .^{5}$

The probability of being offered health insurance at work and the labor productivity shock $z$ evolve jointly with a finite-state Markov process. As we discuss more in the calibration section, we do this because firms' offer rates differ significantly across income groups. Moreover, for workers, the availability of such benefits is highly persistent and the degree of persistence varies according to the income shocks. The transition matrix $\Pi_{Z, E}$ has the dimension $\left(N_{z} \times 2\right) \times\left(N_{z} \times 2\right)$, with an element $p_{Z, E}\left(z, i_{E} ; z^{\prime}, i_{E}^{\prime}\right)=\operatorname{prob}\left(z_{t+1}=z^{\prime}, i_{E, t+1}=i_{E}^{\prime} \mid z_{t}=z, i_{E, t}=i_{E}\right)$. $i_{E}$ is an indicator function, which takes a value 1 if the agent is offered group health insurance and 0 otherwise. Notice that the transition probability is conditional on not aging.

We assume that all old agents are enrolled in the Medicare program. Each old agent pays a fixed premium $p_{\text {med }}$ every period for Medicare and the program will cover the fraction $q_{\text {med }}(x)$ of the total medical expenditures. Young agents pay the Medicare $\operatorname{tax} \tau_{\text {med }}$ that is proportional to the labor income. We assume that old agents do not purchase individual health insurance and their health costs are covered by Medicare and their own resources, plus social insurance if applicable. ${ }^{6}$

Health expenditures $x$ follow a finite-state Markov process. For the two generations $j=$ $y$ (young) or $o$ (old), expenditure shocks are drawn from the generation-specific set $\mathbb{X}^{j}=$ $\left\{x_{1}^{j}, x_{2}^{j}, \ldots, x_{N_{x}}^{j}\right\}$, with a transition matrix $\Pi_{x}^{j}$, where probability is defined as $p_{x}\left(x, x^{\prime}\right)=\operatorname{prob}\left(x_{t+1}=\right.$ $\left.x^{\prime} \mid x_{t}=x\right)$. We assume that if a young agent becomes old, he makes a draw from the set $\mathbb{X}^{o}$ according to the transition matrix of the old agents, conditional upon the state in the previous period.

\footnotetext{
${ }^{5}$ There are other important features and issues in the individual insurance market. In particular, limited information of insurers on the health status of individuals could cause adverse selection, raise the insurance premium and shrink the market as analyzed in Rothschild and Stiglitz (1976). Other issues include coverage exclusion of pre-existing health conditions, overuse of medical services due to generous deductible and copayments (moral hazard), etc. We do not model them in the benchmark economy in order to keep the model tractable.

${ }^{6}$ Many old agents purchase various forms of supplementary insurance, but the fraction of health expenditures covered by such insurance is relatively small and it is only $15 \%$ of total health expenditures of individuals above age 65 (MEPS, 2001), and we choose to assume away the individual insurance market for the old. $97 \%$ of people above age 65 are enrolled in Medicare and the program covers $56 \%$ of their total health expenditures. For more on the health insurance of the old, see for example Cutler and Wise (2003).
} 


\section{$2.4 \quad$ Preferences}

Preferences are assumed to be time-separable with a constant subjective discount factor $\beta$. Oneperiod utility from consumption is defined as a CES form, $u(c)=\frac{c^{1-\sigma}}{1-\sigma}$, where $\sigma$ is the coefficient of relative risk aversion.

\subsection{Firms and production technology}

A continuum of competitive firms operate a technology with constant returns to scale. Aggregate output is given by

$$
F(K, L)=A K^{\alpha} L^{1-\alpha},
$$

where $K$ and $L$ are the aggregate capital and labor efficiency units employed by the firm's sector and $A$ is the total factor productivity, which we assume is constant. Capital depreciates at rate $\delta$ every period.

As discussed above, if a firm offers employer-based health insurance benefits to its employees, a fraction $\psi \in[0,1]$ of the insurance premium is paid at the firm level. The firm needs to adjust the wage to ensure the zero profit condition. The $\operatorname{cost} c_{E}$ is subtracted from the marginal product of labor, which is just enough to cover the total premium cost that the firm has to pay. ${ }^{7}$ The adjusted wage is given as

$$
w_{E}=w-c_{E}
$$

where $w=F_{L}(K, L)$ and $c_{E}$, the employer's cost of health insurance per efficiency unit, is defined as

$$
c_{E}=\mu_{E}^{i n s} p \psi \frac{1}{\sum_{k=1}^{N_{z}} z_{k} \bar{p}_{Z, E}\left(k \mid i_{E}=1\right)},
$$

where $\mu_{E}^{i n s}$ is the fraction of workers that purchase health insurance, conditional on being offered such benefits, i.e. $i_{E}=1 . \bar{p}_{Z, E}\left(k \mid i_{E}=1\right)$ is the stationary probability of drawing productivity

\footnotetext{
${ }^{7}$ The assumption behind this wage setting rule is that a firm does not adjust salary according to individual states of a worker. A firm simply employs efficiency units optimally that consist of a mix of workers of different states according to their distribution. The employer-based insurance system with a competitive firm in essence implies a transfer of a subsidy from uninsured to insured workers. Our particular wage setting rule assumes the subsidy for each worker per efficiency unit is the same across agents in the firm.

An alternative is to assume that a firm adjusts the wage conditional on the purchase decision of group insurance by each agent (i.e. the wage adjustment depends on all the state variables of an agent) or on some sates. We made our choice in light of realism.
} 
$z_{k}$ conditional on $i_{E}=1 .^{8}$

\subsection{The government}

We impose government budget balance period by period. The social security and Medicare systems are self-financed by proportional taxes $\tau_{s s}$ and $\tau_{m e d}$ on labor income.

There is a "safety net" provided by the government, which we call social insurance. The government guarantees a minimum level of consumption $\bar{c}$ for every agent by supplementing the income in case the agent's disposable assets fall below $\bar{c}$, as in Hubbard, Skinner and Zeldes (1995). The social insurance program stands in for all other social assistance programs such as Medicaid and food stamp programs.

The government levies tax on income and consumption to finance expenditures $G$ and the social insurance program. Labor and capital income are taxed according to a progressive tax function following Gouveia and Strauss (1994) and consumption is taxed at a proportional rate $\tau_{c}$. We provide more details on the tax system below.

\subsection{Households}

The state for a young agent is summarized by a vector $s_{y}=\left(a, z, x, i_{H I}, i_{E}\right)$, where $a$ is assets brought into the period, $z$ is the idiosyncratic shock to productivity, $x$ is the idiosyncratic health expenditure shock from the last period that has to be paid in the current period and $i_{H I}$ is an indicator function that takes a value 1 if the agent held health insurance in the last period and 0 otherwise. The indicator function $i_{E}$ signals the availability of employer-based health insurance benefits in the current period.

The timing of events is as follows. A young agent observes the state $\left(a, z, x, i_{H I}, i_{E}\right)$ at the beginning of the period, then pays last period's health care bill $x$, makes the consumption and savings decision, pays taxes and receives transfers and also decides on whether to be covered by health insurance. After the agent has made all decisions, this period's health expenditure shock $x^{\prime}$ and next period's generation, i.e. whether he retires or not, and productivity and offer status are revealed. Together with allocational decisions $a^{\prime}$ and $i_{H I}^{\prime}$ they form next period's state

\footnotetext{
${ }^{8}$ It is easy to verify that this wage setting rule satisfies the zero profit condition of a firm that employs labor $N: w N=($ total salary $)+($ total insurance costs paid by the firm $)$.
} 
$s_{y}^{\prime}=\left(a^{\prime}, z^{\prime}, x^{\prime}, i_{H I}^{\prime}, i_{E}^{\prime}\right)$. The agent makes the health insurance decision $i_{H I}^{\prime}$ after he or she finds out whether the employer offers group insurance but before the health expenditure shock for the current period $x^{\prime}$ is known. Also notice that agents pay an insurance premium one period before the expenditure payment occurs. Therefore the insurance company also earns interest on the premium revenues accrued during one period.

Since the arrangements for the health expenditure payment differ between young workers and retirees and agents pay their health care bills with a one period lag, we have to distinguish between recently retired agents and the rest of the old agents. The former, which we call a 'recently retired agent', has to pay the health care bill of his last year, potentially covered by an insurance contract he purchased as a young agent, while an existing old person, which we call simply an 'old agent', is covered by Medicare. As a result, the state for recently aged agents is given as $s_{r}=\left(a, x, i_{H I}\right)$ and for the other old agents $s_{o}=(a, x)$.

We write the maximization problems of all three generations of agents (young, recently retired and old) in a recursive form. In the value functions the subscript denotes the generation of an agent, where $y$ stands for young agents, $r$ stands for recently retired and $o$ refers to old agents:

\section{Young agents' problem}

$$
V_{y}\left(s_{y}\right)=\max _{c, a^{\prime}, i_{H I}^{\prime}}\left\{u(c)+\beta\left\{\left(1-\rho_{o}\right) E\left[V_{y}\left(s_{y}^{\prime}\right)\right]+\rho_{o} E\left[V_{r}\left(s_{r}^{\prime}\right)\right]\right\}\right\}
$$

subject to

$$
\begin{aligned}
\left(1+\tau_{c}\right) c+a^{\prime}+\left(1-i_{H I} \cdot q(x)\right) x & =\tilde{w} z-\tilde{p}+(1+r)\left(a+T_{B}\right)-\text { Tax }+T_{S I} \\
i_{H I}^{\prime} & \in\{0,1\} \\
a^{\prime} & \geq \underline{a}
\end{aligned}
$$


where

$$
\begin{aligned}
\tilde{w} & = \begin{cases}\left(1-0.5\left(\tau_{\text {med }}+\tau_{s s}\right)\right) w & \text { if } i_{E}=0 \\
\left(1-0.5\left(\tau_{\text {med }}+\tau_{s s}\right)\right)\left(w-c_{E}\right) & \text { if } i_{E}=1\end{cases} \\
\tilde{p} & = \begin{cases}p \cdot(1-\psi) & \text { if } i_{H I}^{\prime}=1 \text { and } i_{E}=1 \\
p_{m}(x) & \text { if } i_{H I}^{\prime}=1 \text { and } i_{E}=0 \\
0 & \text { if } i_{H I}^{\prime}=0\end{cases} \\
T a x & =T(y)+0.5\left(\tau_{m e d}+\tau_{s s}\right)\left(\tilde{w} z-i_{E} \cdot \tilde{p}\right) \\
y & =\max \left\{\tilde{w} z+r\left(a+T_{B}\right)-i_{E} \cdot \tilde{p}, 0\right\} \\
T_{S I}= & \max \left\{0,\left(1+\tau_{c}\right) \bar{c}+\left(1-i_{H I} \cdot q(x)\right) x+T(\tilde{y})-\tilde{w} z-(1+r)\left(a+T_{B}\right)\right\} \\
\tilde{y} & =\tilde{w} z+r\left(a+T_{B}\right)
\end{aligned}
$$

The young agents' choice variables are $\left(c, a^{\prime}, i_{H I}^{\prime}\right)$, where $c$ is consumption, $a^{\prime}$ is the riskless savings and $i_{H I}^{\prime}$ is the indicator variable for this period's health insurance which covers expenditures that show up in next period's budget constraint. Remember that the current state $x$ is last period's expenditure shock while the current period's expenditure $x^{\prime}$ is not known when the agents makes the insurance coverage decision. Agents retire with probability $\rho_{o}$, in which case the agent's value function will be that of a recently retired old, $V_{r}\left(s_{o}^{\prime}\right)=V_{r}\left(a^{\prime}, x^{\prime}, i_{H I}^{\prime}\right)$, as defined below.

Equation (5) is the flow budget constraint of a young agent. Consumption, saving, medical expenditures and payment for the insurance contract must be financed by labor income, saving from previous period and a lump sum bequest transfer plus accrued interest $(1+r)\left(a+T_{B}\right)$, net of income and payroll taxes Tax plus social insurance transfer $T_{S I}$ if applicable. $a^{\prime}$ cannot exceed the borrowing limit $\underline{a}$. $\tilde{w}$ is the wage per efficiency unit already adjusted by the employer's portion of payroll taxes and benefits cost as specified in equation (6). If the agent's employer does not offer health insurance benefits, it equals $\left(1-0.5\left(\tau_{\text {med }}+\tau_{s s}\right)\right) w$, that is, the marginal product of labor net of employer payroll taxes. If the employer does offer insurance, the wage is reduced by both $c_{E}$, which is the health insurance cost paid by a firm as defined in equations (2) and (3), and the payroll tax. Consequently, one could interpret the $\tilde{w} z$ as the gross salary.

Payroll taxes are imposed on the wage income net of paid insurance premium if it is provided 
through an employer, as shown in the RHS of equation (8). ${ }^{9}$ Equation (9) represents the income tax base; labor income paid to a worker plus accrued interest on savings and bequests less the insurance premium, again provided that the purchase is through the employer. The taxes are bounded below by zero.

The term $T_{S I}$ in equation (10) is a government transfer that guarantees a minimum level $\bar{c}$ of consumption for each agent after receiving income, paying taxes and health care costs. The health insurance premium for a new contract is not covered under the government's transfer program.

The marginal cost of the insurance premium $\tilde{p}$ depends on the state $i_{E}$ as given in equation (7). ${ }^{10}$

\section{Recently retired agents' problem}

$$
V_{r}\left(s_{r}\right)=\max _{c, a^{\prime}}\left\{u(c)+\beta\left(1-\rho_{d}\right) E\left[V_{o}\left(s_{o}^{\prime}\right)\right]\right\}
$$

subject to

$$
\begin{aligned}
\left(1+\tau_{c}\right) c+a^{\prime}+\left(1-i_{H I} \cdot q(x)\right) x= & s s-p_{\text {med }}+(1+r)\left(a+T_{B}\right)-T(y)+T_{S I} \\
y= & r\left(a+T_{B}\right) \\
T_{S I}= & \max \left\{0,\left(1+\tau_{c}\right) \bar{c}+\left(1-i_{H I} \cdot q(x)\right) x\right. \\
& \left.+p_{\text {med }}-s s-(1+r)\left(a+T_{B}\right)+T(y)\right\} \\
a^{\prime} \geq & \underline{a}
\end{aligned}
$$

\footnotetext{
${ }^{9}$ To be precise, the payroll tax base at each of firm and individual levels is bounded below by zero, and we have

$$
\operatorname{Tax}=T(y)+0.5\left(\tau_{m e d}+\tau_{s s}\right) \cdot \max \left\{\tilde{w} z-i_{E} \cdot \tilde{p}, 0\right\} .
$$

For simplicity we present it as in equation (8), which is applicable when the zero boundary condition does not bind. The zero lower bound condition also applies for the employer portion of payroll taxes.

${ }^{10}$ Agents who are offered insurance by employers also have access to the individual insurance market and can purchase a contract at the market price, which depends on the individual health status. Given the same coverage ratios offered by each contract, agents choose to be insured at the lowest cost taking into account the tax break which can be applied only when they choose to purchase an employer-based contract. In our benchmark model, however, no one chooses to buy an individual contract in such a case since the fraction $\psi$ paid by employers makes an employer-based contract more attractive. This holds even for agents with the best health condition, who could buy a contract in the market at the lowest price. Hence we write the premium as $\tilde{p}=p(1-\psi)$, when $i_{E}=1$ and $i_{H I}^{\prime}=1$.
} 


\section{Old agents' problem}

$$
V_{o}\left(s_{o}\right)=\max _{c, a^{\prime}}\left\{u(c)+\beta\left(1-\rho_{d}\right) E\left[V_{o}\left(s_{o}^{\prime}\right)\right]\right\}
$$

subject to

$$
\begin{aligned}
\left(1+\tau_{c}\right) c+a^{\prime}+\left(1-q_{\text {med }}(x)\right) x= & s s-p_{\text {med }}+(1+r)\left(a+T_{B}\right)-T(y)+T_{S I} \\
y= & r\left(a+T_{B}\right) \\
T_{S I}= & \max \left\{0,\left(1+\tau_{c}\right) \bar{c}+\left(1-q_{\text {med }}(x)\right) x\right. \\
& \left.+p_{\text {med }}-s s-(1+r)\left(a+T_{B}\right)+T(y)\right\} \\
a^{\prime} \geq & \underline{a}
\end{aligned}
$$

The choice variables of the two old generations are $c, a^{\prime}$. The social security benefit payment is denoted by $s s$ and $p_{m e d}$ is the Medicare premium that each old agent pays. The only difference between the budget constraints of the two old generations is how health expenditures $x$ are financed. The old agents are covered by Medicare for a fraction $q_{m e d}(x)$ of $x$ and the recently retired agents are covered for $q(x)$ if they purchased an insurance contract in the previous period.

\subsection{Health insurance company}

The health insurance company is competitive. It charges premia $p$ and $p_{m}(x)$ that precisely cover all expenditures on the insured. Moreover, we assume that there is no cross-subsidy across contracts, i.e. group and individual insurance contracts (for each health status) are self-financed and satisfy:

$$
\begin{aligned}
(1+r) p & =\frac{\left(1+\phi_{G}\right) \int \sum_{x^{\prime}} p_{y}\left(x^{\prime} \mid x\right) x^{\prime} q\left(x^{\prime}\right) i_{E} i_{H I}^{\prime}(s) \mu(s \mid j=y) d s}{\int i_{E} i_{H I}^{\prime}(s) \mu(s \mid j=y) d s} \\
(1+r) p_{m}(x) & =\frac{\left(1+\phi_{I}\right) \int \sum_{x^{\prime}} p_{y}\left(x^{\prime} \mid x\right) x^{\prime} q\left(x^{\prime}\right)\left(1-i_{E}\right) i_{H I}^{\prime}(s) \mu(s \mid x, j=y) d s}{\int\left(1-i_{E}\right) i_{H I}^{\prime}(s) \mu(s \mid x, j=y) d s} \quad \forall x
\end{aligned}
$$

where $\phi_{G}$ and $\phi_{I}$ denote the proportional markup for the group insurance contract and individual insurance contract respectively. The assumption that the insurance company differentiate the 
prices for the health status in the individual market can be interpreted as the agents who apply for the insurance revealing their age, current health condition and past medical history and the insurance company utilizing the information and charging a premium that ensures zero expected profits based on the information.

\subsection{Stationary competitive equilibrium}

At the beginning of the period, each young agent is characterized by a state vector $s_{y}=$ $\left(a, z, x, i_{H I}, i_{E}\right)$, i.e. asset holdings $a$, labor productivity $z$, health care expenditure $x$, and indicator functions for insurance holding $i_{H I}$, and employer-based insurance benefits $i_{E}$. Old agent has the state vector $s_{r}=\left(a, x, i_{H I}\right)$ or $s_{o}=(a, x)$, depending on whether the agent is recently retired or not. Let $a \in \mathbb{A}=\mathbb{R}_{+}, z \in \mathbb{Z}, x \in \mathbb{X}, i_{H I}, i_{E} \in \mathbb{I}=\{0,1\}$ and $j \in \mathbb{J}=\{y, r, o\}$ ( $y$ for the young, $r$ the recently retired old and $o$ for the rest of the old agents) and denote by $\mathbb{S}=\{\mathbb{J}\} \times\left\{\mathbb{S}_{y}, \mathbb{S}_{r}, \mathbb{S}_{o}\right\}$ the entire state space of the agents, where $\mathbb{S}_{y}=\mathbb{A} \times \mathbb{Z} \times \mathbb{X}_{y} \times \mathbb{I}^{2}, \mathbb{S}_{r}=\mathbb{A} \times \mathbb{X}_{o} \times \mathbb{I}$ and $\mathbb{S}_{o}=\mathbb{A} \times \mathbb{X}_{o}$. Let $s \in \mathbb{S}$ denote a general state vector of an agent: $s \in \mathbb{S}_{y}$ if young, $s \in \mathbb{S}_{r}$ if recently retired and $s \in \mathbb{S}_{o}$ if old.

The equilibrium is given by interest rates $r$, wage rate $w$ and adjusted wage $w_{E}$; allocation functions $\left\{c, a^{\prime}, i_{H I}^{\prime}\right\}$ for young and $\left\{c, a^{\prime}\right\}$ for old; government tax system given by income tax function $T(I)$, consumption tax $\tau_{c}$, Medicare, social security and social insurance program; accidental bequests transfer $T_{B}$; the individual health insurance contracts given as pairs of premium and coverage ratios $\{p, q\},\left\{p_{m}(x), q\right\}$; a set of value functions $\left\{V_{y}\left(s_{y}\right)\right\}_{s_{y} \in \mathbb{S}_{y}},\left\{V_{r}\left(s_{r}\right)\right\}_{s_{r} \in \mathbb{S}_{r}}$ and $\left\{V_{o}\left(s_{o}\right)\right\}_{s_{o} \in \mathbb{S}_{o}}$; and distribution of households over the state space $\mathbb{S}$ given by $\mu(s)$,

such that

1. Given the interest rates, the wage, the government tax system, Medicare, social security and social insurance program, and the individual health insurance contract, the allocations solve the maximization problem of each agent.

2. The riskless rate $r$ and wage rate $w$ satisfy marginal productivity conditions, i.e. $r=$ $F_{K}(K, L)-\delta$ and $w=F_{L}(K, L)$, where $K$ and $L$ are total capital and labor employed in the firm's sector. 
3. A firm that offers employer-health insurance benefits pays the wage net of cost, given as $w_{E}=w-c_{E}$, where $c_{E}$ is the cost of health insurance premium per efficiency unit paid by a firm, as defined in equation (3).

4. The accidental bequests transfer matches the remaining assets (net of health care expenditures) of the deceased.

$$
T_{B}=\rho_{d} \int\left[a^{\prime}(s)-\sum_{x^{\prime}} p_{o}\left(x^{\prime} \mid x\right)\left\{\left(1-q_{\text {med }}\left(x^{\prime}\right)\right) x^{\prime}\right\}\right] \mu(s \mid j=r, o) d s
$$

5. The health insurance company is competitive, and satisfies conditions (11) and (12).

6. The government's primary budget is balanced.

$$
G+\int T_{S I}(s) \mu(s) d s=\int\left[\tau_{c} c(s)+T(y(s))\right] \mu(s) d s
$$

where $y(s)$ is the taxable income for an agent with a state vector $s$.

7. Social security system is self-financing.

$$
s s \int \mu(s \mid j=r, o) d s=\tau_{s s} \int\left(\tilde{w} z-0.5 i_{H I}^{\prime} \cdot i_{E} \cdot p(1-\psi)\right) \mu(s \mid j=y) d s
$$

8. Medicare program is self-financing.

$$
\begin{aligned}
\int q_{\text {med }}(x) x \mu(s \mid j & =o) d s=\tau_{\text {med }} \int\left(\tilde{w} z-0.5 i_{H I}^{\prime} \cdot i_{E} \cdot p(1-\psi)\right) \mu(s \mid j=y) d s \\
+p_{\text {med }} \int \mu(s \mid j & =r, o) d s
\end{aligned}
$$

9. Capital and labor markets clear.

$$
\begin{aligned}
K & =\int\left[a(s)+T_{B}\right] \mu(s) d s+\int i_{H I}^{\prime}\left(i_{E} p+\left(1-i_{E}\right) p_{m}(x)\right) \mu(s \mid j=y) d s \\
L & =\int z \mu(s \mid j=y) d s
\end{aligned}
$$


10. The aggregate resource constraint of the economy is satisfied.

$$
G+C+X=F(K, L)-\delta K
$$

where

$$
\begin{aligned}
C & =\int c(s) \mu(s) d s \\
X & =\int x(s) \mu(s) d s .
\end{aligned}
$$

11. The law of motion for the distribution of agents over the state space $\mathbb{S}$ satisfies

$$
\mu_{t+1}=R_{\mu}\left(\mu_{t}\right)
$$

where $R_{\mu}$ is a one-period transition operator on the distribution.

\section{Calibration}

In this section, we outline the calibration of the model. Table 1 summarizes the values and describes the parameters.

\subsection{Demographics}

A model period corresponds to one year. We define the generations as follows. Young agents are between the ages of 20 and 64, while old agents are 65 and over. Young agents' probability of aging $\rho_{o}$ is set at $1 / 45$ so that they stay for an average of 45 years in the labor force before retirement. The death probability $\rho_{d}$ is calibrated so that the old agents above age 65 constitute $20 \%$ of the population, based on the panel data set we discuss below. This is a slight deviation from the fraction of $17.4 \%$ in the Census because we restrict our attention to head of households. We abstract from population growth and the demographic structure remains the same across periods. Every period a measure $\frac{\rho_{d} \rho_{o}}{\rho_{d}+\rho_{o}}$ of young agents enter the economy to replace the deceased old agents. 


\subsection{Endowment, health insurance and health expenditures}

\subsubsection{Data source}

For endowment, health expenditure shocks and health insurance, we use income and health data from one source, the Medical Expenditure Panel Survey (MEPS), which is based on a series of national surveys conducted by the U.S. Agency for Health Care Research and Quality (AHRQ). The MEPS consists of seven two-year panels 1996/1997 up to 2002/2003 and includes data on demographics, income and most importantly health expenditures and insurance. We drop the first three panels because one crucial variable that we need in determining the joint endowment and insurance offer process is missing in those panels.

To calibrate an income process, we consider wage income of all heads of households (both male and female) with non-negative income defined as the sum of labor, business and sales income, unlike many existing studies in the literature on stochastic income process (for example, Storesletten, et al (2004), who use households to study earnings process, and Heathcote, et al (2004), who use white male heads of households to estimate wage process). The main reason for not relying on those studies is that we want to capture the individual characteristics associated with health insurance and health expenditures across the dimension of the income shocks. It is possible only by using a comprehensive database like MEPS.

As a sample unit we choose individuals rather than households to better capture the process for individual health expenditures. Treating health expenditures of a family unit would require adjusting them for different family sizes to fit in our model and will inevitably bias the estimates of expenditure and income persistence. We choose heads instead of all individuals since many non-head individuals are covered by their spouses' health insurance. Our model also captures those with zero or very low level of assets, who would be eligible for public welfare assistance. Many households that fall in this category are headed by females, which is why we include both males and females. In addition, most of the existing studies on the income process are focused on samples with strictly positive income, often above some threshold level and such treatment does not fit in our model, either.

Our definition of a household is based on the Health Insurance Eligibility Unit (HIEU) defined in the MEPS database. A HIEU is a unit that includes adults and other family members who are 
eligible for coverage under family insurance plans. The unit includes spouses, unmarried natural or adoptive children of age 18 or under and children under 24 who are full-time students. The definition of a head is the single adult member in case of an unmarried couple. For a household with a married couple, we choose the one with a higher income as the head of the households.

Since for young agents we estimate a joint process of income and the group insurance offer status we restrict our attention to those agents that can be uniquely identified as either being offered or not being offered insurance. ${ }^{11}$ For consistency purposes we also restrict our attention to the same set of agents when we calibrate the health expenditure process for young agents.

\subsubsection{Endowment}

We calibrate the endowment process jointly with the stochastic probability of being offered employer-based health insurance. For the income process, we avoid the detour of first estimating an $\mathrm{AR}(1)$ process and then discretizing with the methods of Tauchen (1986). Instead, we specify the income distribution over the five income states so that in each year, an equal number of agents belong to each of the five bins of equal size. Then we determine for each individual in which bin he or she resides in the two consecutive years and thus construct the joint transition probabilities $p_{Z, E}\left(z, i_{E} ; z^{\prime}, i_{E}^{\prime}\right)$ of going from income bin $z$ with insurance status $i_{E}$ to income bin $z^{\prime}$ with $i_{E}^{\prime}$. Recall $i_{E}$ is an indicator function that takes a value 1 if employer-based health insurance is offered and 0 otherwise. The joint Markov process is defined over $N_{z} \times 2$ states with a transition matrix $\Pi_{Z, E}$ of size $\left(N_{z} \times 2\right) \times\left(N_{z} \times 2\right)$. We average the transition probabilities over the five panels weighted by the number of people in each panel. We display the transition matrix in Appendix A.

Finally, in order to get the grids for $z$, we compute the average income in each of the five bins in 2002 dollars and it is given as below. In the computation, we normalize the grids so that

\footnotetext{
${ }^{11}$ Agents that are offered insurance can be easily identified in MEPS by the corresponding dummy variable. Notice that in the data by definition only those agents that are employed can have an insurance offer status. Since we want to generate an income process for both employed and unemployed agents, we consider agents not offered insurance being those that according to MEPS are employed and not offered insurance plus those not currently employed who will have an "inapplicable" offer status. This implies that we disregard about $10 \%$ of the people in the MEPS, namely those that are employed but have unknown/inapplicable insurance offer status and those with unknown employment status. This restriction will not change the shape of the Markov processes in any systematic way. For example comparing the transition probabilities between income groups (unconditional on insurance offer status) between the full and the restricted sample does not generate substantial differences.
} 
the average is one.

$$
\mathbb{Z}=\{\$ 409, \$ 10,209, \$ 20,862, \$ 33,922, \$ 70,105\}
$$

Notice that the income shocks look quite different from the ones normally used in the literature in that we include all heads of households, even those with zero income. This generates an extremely low income shock of near zero for a sizeable measure of the population. We assume that the agents cannot borrow, i.e. $\underline{a}=0$. Given that the lowest possible income is very small, the constraint is equivalent to imposing a natural borrowing limit.

The stationary distribution over the $\left(N_{z} \times 2\right)$ grids is given as

\begin{tabular}{l|ccccc|c}
$z$ grid number & 1 & 2 & 3 & 4 & 5 & sum \\
\hline GHI offered (\%) & 0.6 & 7.3 & 12.9 & 16.5 & 18.9 & 56.2 \\
GHI not offered (\%) & 19.8 & 12.1 & 6.2 & 3.2 & 2.5 & 43.8
\end{tabular}

There is an asymmetry in the income distribution for the agents with a group insurance offer and those without such an offer. A high income is more likely to be accompanied with the group insurance offer.

\subsubsection{Health expenditure shocks}

In the same way as for the endowment process, we estimate the process of health expenditure shocks and the transition probabilities directly from the MEPS data. We use seven states for the expenditures and for each of the young and the old generations, we specify the bins of size $(20 \%, 20 \%, 20 \%, 20 \%, 15 \%, 4 \%, 1 \%)$. Young agents' expenditure grids are given as

$$
\mathbb{X}_{y}=\{0.000,0.007,0.027,0.070,0.183,0.533,1.545\}
$$

which are the mean expenditures in the seven bins in the first year of the last panel, that is, in the year 2002. The transition matrices for each young generation are displayed in Appendix A. The expenditures are normalized in terms of their ratios to the average labor income in 2002. 
This parametrization generates average expenditures of $7.9 \%$ of mean labor income in the young generation or $\$ 2,357$ in year 2002 dollars.

Notice that an advantage of our procedure is that we can specify the bins ourselves. Average expenditures in the first and second bins are less than $1 \%$ of average labor income. In contrast, expenditures are substantial in the top bins. For example, the top $1 \%$ of the third generation have average expenditures of more than 1.5 times the average income (over $\$ 46,000$ in 2001). The next $4 \%$ have average expenditures of $50 \%$ of average income $(\$ 16,000)$ while the following $15 \%$ spend less than $20 \%$ of average income $(\$ 5,500)$.

Likewise, using the same strategy for the old generation (common for $j=r$ and $o$ ) we obtain the expenditure grids

$$
\mathbb{X}_{o}=\{0.007,0.047,0.100,0.199,0.507,1.299,2.542\}
$$

and the transition matrix displayed in Appendix A, which generates unconditional expectation of $x_{o}$ of $20.8 \%$ of mean income or $\$ 6,700$ in year 2002 dollars.

\subsection{Health insurance}

The coverage ratios of health insurance contracts are calibrated using the same four MEPS panels. Given that the coverage depends on and increases in the health expenditures incurred by the insured, we estimate a polynomial $q(x)$, the coverage ratio as a function of expenditures $x$. More details on the calibration of this function are given in Appendix B.

There is a proportional operational cost incurred by insurance companies, which is passed through to the insurance premiums as a mark-up. We assume that this cost is a waste ('thrown away into the ocean') and does not contribute to anything. The parameter $\phi_{I}$ for the individual contract is calibrated so that the model achieves the overall take-up ratio of $42 \%$ as in the MEPS data when the group insurance is not offered. We assume the same the cost is added to the group insurance contract, i.e. $\phi_{G}=\phi_{I}$.

The group premium $p$ is determined in equilibrium to ensure zero profits for the insurance company in the group insurance market. The average annual premium of an employer-based health insurance was $\$ 2,051$ in 1997 or about $7 \%$ of annual average labor income (Sommers 
(2002)). Model simulations yields a premium of $6.23 \%$ of average annual labor income.

A firm offering employer-based health insurance pays a fraction $\psi$ of the premium. According to the MEPS, the average percent of total premium paid by employee varies between $11 \%$ and 23\% depending on the industry in 1997 (Sommers, 2002). Other studies estimate figures in a similar range and we set it to $20 \% .^{12}$

With regards to individual health insurance, the insurance company sets $p_{m}(x)$ to satisfy the equation (12), that is,

$$
p_{m}(x)=\left(1+\phi_{I}\right) E\left\{q\left(x^{\prime}\right) x^{\prime} \mid x\right\} /(1+r) .
$$

The expectation is with respect to the next period's expenditures $x^{\prime}$, and we compute the premium using the transition matrix $\Pi_{x_{y}}$ as a function of last period's expenditures. In the benchmark model, the premiums in the unit of average labor income are given as follows.

\begin{tabular}{cccccccc} 
bin & 1 & 2 & 3 & 4 & 5 & 6 & 7 \\
\hline$p_{m}(x)$ & 0.0124 & 0.0261 & 0.0518 & 0.0774 & 0.1299 & 0.2292 & 0.3806
\end{tabular}

\subsection{Preferences}

We calibrate the annual discount factor $\beta$ to achieve an aggregate capital output ratio $K / Y=3.0$ and choose a risk aversion parameter of $\sigma=2$, following the literature on consumption See, for example, Attanasio (1999) and Gourinchas and Parker (2002).

\subsection{Technology}

Total factor productivity $A$ is normalized so that the average labor income equals one in the benchmark. ${ }^{13}$ As is standard in the literature, the capital share is $\alpha$ equals 0.33 . For the depreciation rate, we pick $\delta=0.06$.

\footnotetext{
${ }^{12} 15.1 \%$ by National Employer Health Insurance Survey of the National Center for Health Statistics in 1993 and $16 \%$ by Employer Health Benefits Survey of the Kaiser Family Foundation in 1999.

${ }^{13}$ Average income per person in our samples was $\$ 29,950$ in 2002.
} 


\subsection{Government}

\subsubsection{Expenditures and taxation}

The value for $G$, that is, the part of government spending not dedicated to social insurance transfers, is exogenously given and it is fixed across all policy experiments. We calibrate it to $18 \%$ of GDP in the benchmark economy in order to match the share of government consumption and gross investment excluding transfers, at the federal, state and local levels (The Economic Report of the President, 2004). We set the consumption tax rate $\tau_{c}$ at $5.67 \%$, based on Mendoza, Razin and Tesar (1994). ${ }^{14}$

The income tax function consists of two parts, a non-linear progressive income tax and proportional tax on income. The progressive part mimics the actual income tax in the U.S. following the functional form studied by Gouveia and Strauss (1994), while the proportional part stands in for all other taxes, that is, non-income and non-consumption taxes, which for simplicity we lump together into a single proportional tax $\tau_{y}$ levied on income. The functional form is given as

$$
T(y)=a_{0}\left\{y-\left(y^{-a_{1}}+a_{2}\right)^{-1 / a_{1}}\right\}+\tau_{y} y
$$

Parameter $a_{0}$ is the limit of marginal taxes in the progressive part as income goes to infinity, $a_{1}$ determines the curvature of marginal taxes and $a_{2}$ is a scaling parameter. To preserve the shape of the tax function estimated by Gouveia and Strauss, we use their parameter estimates $\left\{a_{0}, a_{1}\right\}=\{0.258,0.768\}$ and choose the scaling parameter $a_{2}$ such that the share of government expenditures raised by the progressive part of the tax function $a_{0}\left\{y-\left(y^{-a_{1}}+a_{2}\right)^{-1 / a_{1}}\right\}$ equals $65 \%$. This matches the fraction of total revenues financed by income tax according to the OECD Revenue Statistics. The parameter $a_{2}$ is calibrated within the model because it depends on other endogenous variables. The parameter $\tau_{y}$ in the proportional term is chosen to balance the overall government budget and it, too, will be determined in the model's equilibrium.

\footnotetext{
${ }^{14}$ The consumption tax rate is the average over the years 1965-1996. The original paper contains data for the period 1965-1988 and we use an unpublished extension for 1989-1996 for recent data available on Mendoza's webpage.
} 


\subsubsection{Social insurance program}

The minimum consumption level $\bar{c}$ to be eligible for social insurance is calibrated so that the model achieves the target share of households with a low level of assets. Households with net worth of less than $\$ 5,000$ constitute $20.0 \%$ (taken from Kennickell, 2003, averaged over 1989, 1992, 1995, 1998 and 2001 SCF data, in 2001 dollars) and we use this figure as a target to match in the benchmark equilibrium.

\subsubsection{Social security system}

We set the replacement ratio at $45 \%$ based on the study by Whitehouse (2003). In equilibrium, the total benefit payment equals the total social security tax revenues. The social security tax rate is pinned down in the model given that the system is self-financed. We obtain the social security tax rate $\tau_{s s}=10.58 \%$, which is close to the current Old-Age and Survivors Insurance (OASI) part of the social security tax rate, $10.6 \%$.

\subsubsection{Medicare}

We assume every old agent is enrolled in Medicare Part A and Part B. We use the MEPS data to calculate the coverage ratio of Medicare in the five expenditure bins $x_{o} \in \mathbb{X}_{o}$.

\begin{tabular}{cccccccc} 
bin & 1 & 2 & 3 & 4 & 5 & 6 & 7 \\
\hline$q_{\text {med }}(x)$ & 0.267 & 0.294 & 0.318 & 0.377 & 0.554 & 0.701 & 0.641
\end{tabular}

The Medicare premium for Part B was $\$ 799.20$ annually in the year 2004 or about $2.11 \%$ of annual GDP (\$37,800 per person in 2004) which is the ratio that we use in the simulations. The Medicare tax rate $\tau_{m e d}$ is determined within the model so that the Medicare system is self-financed. The model generates expenditures and revenues equal to $1.91 \%$ of labor income. ${ }^{15}$

\footnotetext{
${ }^{15}$ This figure is lower than in reality (Medicare tax rate $2.9 \%$ with its expenditures of about $2.3 \%$ of GDP) for two reasons. First, in our model Medicare is reserved exclusively for the old generation while the actual Medicare system pays for certain expenditures even for young agents. Second, payroll taxes apply to all of labor income while in reality there is a threshold level of currently $\$ 87,900$ after which the marginal payroll tax is zero.
} 


\section{Numerical results}

\subsection{Benchmark model}

Although we don't calibrate the model to generate the patterns of health insurance across the dimension of individual states, our model succeeds in matching them fairly well not only quantitatively but in most cases even quantitatively.

The overall health insurance coverage ratio among the young agents is $74.5 \%$ as opposed to $73 \%$ in the data. Figure 1 displays the take-up ratios of the model over the labor income together with the same statistics from the MEPS data. Both in the data and model, the take-up ratios increase in income. If agents are offered group insurance, the take-up ratios are very high since they receive the subsidy from the firm and the tax benefit. As we saw in the calibration section, agents with higher income are more likely to be offered a group insurance and very few agents in the lowest income grid receive such a benefit, which contribute to the lower take-up ratio of low-income agents. Also recall that we capture agents with no labor income and do not impose any income threshold. Many of them also own a low level of assets and are likely to be eligible for the social insurance. In case the agents face a high expenditure shock and can only purchase individual health insurance at a high premium, they may choose to remain uninsured in the hope of receiving the social insurance and having the health cost be covered by the government. At the very low end of the labor income distribution, the take-up ratio is higher in the data than in the model. The fact that people derive income from sources other than the labor and capital as in the model may contribute to the higher coverage.

Figure 2 displays the take-up ratios over the health expenditures. The data shows a fairly flat take-up ratios between 70 and $80 \%$ except for the agents with very low expenditures. Our model also generates a flat pattern of take-up ratios, although we are not very successful at the very low end. One possible reason is our assumption that all the employers pay $80 \%$ of the premium at the firm level, which is based on the average subsidy ratio in the data. In practice, however, different firms cover a varying fraction of the premium and the data may capture some of those agents with a less generous employer subsidy. The healthiest agents with a relatively low expected expenditure may choose not be insured if the employer subsidy is sufficiently low. 


\subsection{Policy experiments}

We now conduct experiments to determine the effect of changes in the tax treatment of health insurance. In the experiments, we treat changes in the government revenue as follows: expenditures $G$, consumption tax rate $\tau_{c}$ and the progressive part of the income tax function remain unchanged from the benchmark. We adjust the proportional tax rate $\tau_{y}$ to balance the government budget. Medicare and social security systems remain self-financed and the revenue will also be affected because the labor income, which is the payroll tax base, changes across experiments. We keep the Medicare premium $p_{m e d}$ (in terms of its ratio to output) at the benchmark level and adjust the tax rate $\tau_{m e d}$ to maintain the balance. For the social security system, we keep the replacement ratio at $45 \%$ and adjust the retirement benefit $s s$ to account for the changes in the average labor income and the tax rate $\tau_{s s}$ to balance the program's budget.

In each experiment, we first compute a steady state outcome under the stationary equilibrium. We then compute the transition dynamics. We assume that in period 0 , the economy is in the steady state of the benchmark economy. In period 1, an unanticipated change of the policy is announced and implemented and the economy starts to make a transition to the new steady state. Throughout the transition, the proportional tax rate $\tau_{y}$ as well as payroll taxes $\tau_{s s}$ and $\tau_{m e d}$ are adjusted to balance the overall budget of the government, social security and the Medicare systems respectively. Also, the health insurance premium will change as the insurance demand evolves over time.

In order to assess the welfare effect of a reform, once we solve for the transition dynamics, we compute the consumption equivalent variation (" $C E V$ "). It measures the constant increment in percentage of consumption in every state of the world that has to be given to the agent so that he is indifferent between remaining in the benchmark and moving to another economy which is about to make a transition to the new steady state implied by the alternative policy.

\subsubsection{Abolishing tax deductibility of group premium costs / fixing regressiveness}

In the first set of experiments, we let the government abolish the current deductibility of the group insurance premium for the purpose of income tax. Income tax is collected on the entire 
portion of the premium. The taxable income is given as

$$
y=\tilde{w} z+r\left(a+T_{B}\right)+i_{E} i_{H I}^{\prime} \psi p .
$$

Note that not only is the employee-paid portion $(1-\psi) p$ no longer tax-deductible, but also the portion paid by the employer $\psi p$ is subject to taxation and considered as part of taxable income of the agent. The policy will eliminate the regressiveness of the system and restore the vertical inequality created by the progressiveness of the income tax function.

Experiment results are summarized in Table 2. The top section displays some statistics on health insurance: the premium of group insurance $p$, the overall take-up ratio $T U R_{\text {all }}$, the takeup ratio conditional on not being offered group insurance $T U R_{n o G}$ and offered group insurance $T U R_{G}$. The next two rows Group and Individual show the break-down of $T U R_{G}$, i.e. the fraction of agents who bought group insurance (Group) or individual insurance (Individual) conditional on being offered group insurance. The second section displays aggregate variables including the proportional tax rate $\tau_{y}$ on income that balances the government budget and the third section shows the welfare effects of each reform. $\% w / C E V>0$ indicates the fraction of young agents in the benchmark that would experience a welfare gain (positive $C E V$ ) if the alternative policy is implemented.

The first experiment (experiment 1-A) invokes a radical change - the government abolishes the entire deductibility of the group insurance premium for both income and payroll tax purposes. The policy leads to a partial collapse of the group insurance market. The take-up ratio conditional on being offered group insurance falls from $99.83 \%$ in the benchmark to $74.03 \%$. About one quarter of those who remain insured opt out of the group insurance market and purchase a contract in the individual market. Those are agents in good health who face a lower premium in the individual insurance market. The exit of these agents out of the group insurance market triggers a deterioration of the health quality in the pool of the insured and the group insurance premium $p$ jumps up to $\$ 2,887$, a $54 \%$ increase from the benchmark. The overall coverage ratio falls by as much as $13.3 \%$. The firm's cost of providing the benefit is lower despite the price increase, since much fewer workers take the offer.

Although the wage rate is higher and the proportional tax rate $\tau_{y}$ on income and the social 
security tax rate $\tau_{s s}$ on labor income are lower than in the benchmark due to the increased tax base, they are not enough to compensate for the average welfare loss for the agents with a group insurance offer due to the lower insurance coverage and increased exposure to health expenditure shocks. Agents without the offer will benefit from the lower tax rate and the slightly higher wage. As shown in $\% w / C E V>0$, about half of the workers would experience a welfare gain from such a reform, but the average welfare effect (in $C E V$ ) is slightly negative.

The aggregate capital does not increase significantly in the experiment, although the lower insurance coverage and increased income uncertainty induces more precautionary savings in general. The main reason is that agents who drop out of the insurance market are the healthiest and are less concerned about expenditure shocks in the immediate future. They do not have a strong incentive to increase savings significantly.

In experiment 1-B, the government corrects for regressiveness of the current system and provides the subsidy more equitably. More precisely, the government abolishes the premium deductibility for the income tax purpose as in experiment 1-A, and in exchange returns a lump-sum subsidy for the purchase of group insurance valued at the average income tax rate of the benchmark economy multiplied with the group insurance premium. The idea is that the government returns the increased revenues due to the abolishment of deductions in the form of a lump-sum subsidy to the agents who purchase insurance through their employers.

Compared to the benchmark, this policy is intended to be more beneficial if the agent with a group insurance offer belongs to a lower income group, because under the benchmark the deduction was based on their lower marginal tax rate. The subsidy based on the average tax rate under this policy is common across agents and higher than the benefit deduction from the lower tax bracket. However, as shown in the lower panel of Table 2, the agents with higher income and in good health status drop out of the insurance market, since they no longer receive the large benefit from the tax system. About $12.0 \%$ of those with a group insurance offer will become uninsured and $5.6 \%$ will purchase a contract in the individual market given the changes in the tax benefit. Those who move to the individual market are also the agents in good health and higher income, who used to receive more benefits under the benchmark. Such movement will trigger the increase of the average health costs among those who remain in the group insurance pool, as in experiment 1-A and the group insurance premium will go up by $17 \%$. Although 
the tax credit provides more benefit to the low-income households, the price increase partially offsets the benefit and there is not much change in the take-up ratio among them. The required proportional tax rate $\tau_{y}$ on income is slightly lower than in the benchmark, since the government can collect more tax revenues from the non-linear progressive part of the income tax function. That is, the premium is no longer deductible and added back to the income tax base. This pushes up the marginal tax rate each agent faces given the progressiveness of the tax system.

In terms of welfare, there is no significant effect by this policy. Although the group insurance price is higher, the firm's cost is lower due to the lower take-up. Workers benefit from a marginally lower tax rate on their income and a higher interest rate. The average labor income is slightly higher in spite of the lower marginal product of labor since the offer cost $c_{E}$ is lower. As a consequence, the majority of the workers will experience a welfare gain, but the magnitude of the gain is negligibly small.

\subsubsection{Extending tax deductibility or subsidy to the non-group insurance market}

In the next policy experiments, the government keeps the current tax deductibility for the group insurance premium untouched and aims to correct for the horizontal equity by providing some benefit for the individual insurance market.

Results are summarized in Table 3. In experiment 2-A, we extend the same tax advantage to everyone, i.e. agents who purchase a contract in the individual market can also deduct the premium cost from their income and payroll tax bases. As shown in the top section of Table 3, the policy would increase the individual insurance coverage by more than $30 \%$ and the overall coverage by $15 \%$. Also note that some people with the group health insurance offer drop out of the market and opt for the individual insurance contract. Agents in a good health condition receive a lower price in the individual market and the additional tax benefit makes them now favor the individual coverage. The group insurance price goes up as a result of the healthiest people leaving the pool. An increased cost of providing deduction is reflected in the proportional tax rate $\tau_{y}$ and the social security tax rate $\tau_{s s}$ that are higher than in the benchmark. An increased coverage across the different health status will reduce the precautionary savings and the aggregate capital falls by about $1 \%$.

In terms of welfare, the policy brings a large welfare gain for those without an insurance offer 
from the employer. Despite the decrease in the aggregate consumption in the final steady state, the reform will enable agents to smooth consumption across the states and enhances the overall welfare. The number of agents who are eligible for the social insurance goes down by $1.6 \%$, since agents are better insured and less exposed to a catastrophic health shock that would bring their disposable assets down to hit the minimum consumption level $\bar{c}$.

In experiments $2-\mathrm{B}$ and $2-\mathrm{C}$, the government offers a refundable credit of $\$ 1,000$ for the purchase of individual insurance, if the person is not offered group insurance. The subsidy is capped by the actual cost of insurance. In experiment 2-C, the provision of the subsidy is subject to the income threshold of $\$ 30,000$, above which the subsidy phases out. This policy is close to what has been proposed by the current administration. As shown in Table 3, there is a large effect on the insurance coverage among those without an access to group insurance. The conditional take-up ratio increases from $42 \%$ to $89 \%$ and $81 \%$, respectively.

The comparison of the results in experiments $2-\mathrm{B}$ and $2-\mathrm{C}$ poses a question of costs and efficiency in targeting beneficiaries. By restricting the eligibility to the lower income households in experiment $2-\mathrm{C}$, the required increase in the proportional tax rate $\tau_{y}$ is $0.64 \%$ as opposed to $0.81 \%$ in 2 -B. The policy increases the overall $T U R$ by $17.1 \%$ and $20.7 \%$. It becomes more costly to provide an incentive to be insured if the agent's income is higher. Wealthy households with more assets are better insured by their accumulated savings. Although not imposing any restrictions on the target beneficiaries of the subsidy may be easier to implement both politically and operationally, such a choice has to be balanced against efficiency.

At the bottom of Table 3, we display the take-up ratios across income shocks $z$ and health expenditure shocks $x$. In experiment 2-B, compared to 2-A, there is much larger increase of the take-up ratios among lower-income households. Providing a subsidy as in 2-B and 2-C is more effective than a tax deduction because low-income agents do not pay much tax, or nearly zero at the lowest income level. Therefore, they receive only small benefits from the deduction policy. The credit policy 2-C also works effectively to raise the coverage among the poor, while the coverage among the rich changes little due to the phase-out of the benefit at a high income level. As shown in the take-up ratios over the expenditure shocks $x$, both credit policies encourage the purchase among healthier agents, since they face a lower premium cost, the large part of which can be covered by the subsidy. 
Increased risk-sharing together with the higher tax rate reduce the saving motive and the aggregate capital and output are lower in both 2B and 2C. Despite the increased tax burden and the relatively large fall in the aggregate level of consumption, the gains from the better insurance coverage and an increased protection against expenditure shocks dominate the negative effects and the welfare effect among young agents is positive on average with a CEV of $1.11 \%$ and $1.07 \%$ in the two experiments. The number of agents eligible for the social insurance goes down by 4 to $5 \%$ in the reforms. The vast majority of the agents would support such reform prposals.

\section{Conclusion}

We study the tax policy associated with employer-provided health insurance in a general equilibrium model, where the health insurance decision is endogenous. The model captures various institutions surrounding the different types of health insurance in a parsimonious way, yet it is rich enough to generate insurance demand that closely resembles that observed in the data. We examine the effects of several tax reforms. The experiments indicate that despite some issues entailed in the current tax system, providing some form of subsidy and an incentive for the group insurance coverage has a merit. Employer-provided group insurance has the feature that everyone can purchase a contract at the same premium irrespective of any individual characteristics - most importantly it is independent of current health status. Relatively healthy young agents would have an incentive to opt out of this contract and either self-insure or find a cheaper insurance contract in the individual market. A subsidy on group insurance can therefore encourage even healthy agents to sign up, maintain the diverse health quality of the insurance pool and alleviate the adverse selection problem that plagues the insurance contract. We conduct an experiment that confirms this intuition by showing that a complete removal of the subsidy results in the deterioration of health quality in the group insurance market, a rise in the group insurance premium, a significant reduction in the insurance coverage, which put together reduces the average welfare.

We also find that there is room for significantly increasing the insurance coverage and improving welfare by restructuring the current subsidy system. Extending the benefit to the individual insurance market to restore horizontal equity is effective in raising the overall insurance coverage 
and enhancing welfare if the subsidy is lump-sum. Extending the deductions to the individual insurance on the other hand is less effective since low income households will receive less benefit from such a reform. Providing a refundable credit for the purchase of individual insurance is shown to raise the coverage by more than $20 \%$ and enhance the welfare despite the increase in the tax to finance the additional expenditures of the government.

Our work highlights the importance of studying health policy and insurance in a general equilibrium framework. Equilibrium prices and aggregate variables are affected by changes in policy. For example, changing the tax treatment of health insurance premia affects the composition of agents that sign up and therefore the equilibrium insurance premium. Altering the attractiveness of health insurance also affects precautionary saving motives, which in turn determines factor prices such as wages and interest rates. We have also shown that it is important to capture fiscal consequences of a reform because providing the subsidy will affect the taxes that must be raised from other sources. The changes in insurance demand are shown to affect other government sponsored welfare programs such as Medicaid.

We compute the transition dynamics from the benchmark economy calibrated to the current macroeconomic and institutional environments surrounding the health insurance policies. Since our focus was on the effect of the tax policy, we chose not to alter other institutions and features of the model along the transition. An interesting question as an extension of the current paper will be to ask how agents' insurance and saving decisions as well as the government's fiscal balance will be affected in response to the future changes in those environment, in particular, the rapidly rising health costs and changing demographics. Also, a rather radical policy reform will be the introduction of the national health system. We will leave these subjects to a future and ongoing research. 


\section{References}

[1] Aiyagari, S. R. (1994). Uninsured idiosyncratic risk and aggregate saving. Quarterly Journal of Economics, Vol. 109, No. 3, pp. 659-684.

[2] Attanasio, O. P. (1999). Consumption. In J. B. Taylor and M. Woodford Eds. Handbook of Macroeconomics Vol. 11, Amsterdam, North-Holland.

[3] Bewley, T. F. (1986). Stationary Monetary Equilibrium with a Continuum of Independently Fluctuating Consumers. In W. Hildenbrand and A. Mas-Colell Eds. Contributions to Mathematical Economics in Honor of Gerald Debreu, Amsterdam, North-Holland.

[4] Castaneda, A., J. Diaz-Gimenez and J. Rios-Rull (2005). Accounting for the U.S. Earnings and Wealth Inequality. Journal of Political Economy, Vol. 111, No. 4.

[5] Chatterjee, S., D. Corbae, M. Nakajima and J. Rios-Rull (2005). A Quantitative Theory of Unsecured Consumer Credit with Risk of Default. mimeo, University of Pennsylvania.

[6] Conesa, J. C., S. Kitao and D. Krueger (2006). Taxing Capital? Not a Bad Idea After All! mimeo, New York University.

[7] Conesa, J. C. and D. Krueger (2006). On the Optimal Progressivity of the Income Tax Code. Journal of Monetary Economics, Vol. 53, No. 7, pp. 1425-1450.

[8] Cutler, D. and D. Wise (2003). The US Medical Care System for the Elderly. mimeo, Harvard University.

[9] De Nardi, Mariacristina, Eric French and John Jones (2005). Differential Mortality, Uncertain Medical Expenses, and the Saving of Elderly Singles, Federal Reserve Bank of Chicago working paper.

[10] Domeij, D and J. Heathcote (2004). On the Distributional Effects of Reducing Capital Taxes. International Economic Review, Vol. 45, No. 2, pp. 523-554.

[11] Fernandez-Villaverde, J. and D. Krueger (2004). Consumption over the Life Cycle: Facts from Consumer Expenditure Survey Data. mimeo, University of Pennsylvania.

[12] Gourinchas, P. and J. A. Parker (2002). Consumption over the Life Cycle. Econometrica, Vol. 70, No. 1, pp. 47-89.

[13] Gouveia, M. and R. P. Strauss (1994). Effective federal individual income tax functions: an exploratory empirical analysis. National Tax Journal, Vol. 47, No. 2, pp. 317-339.

[14] Gruber, J. (2004) Tax Policy for Health Insurance. NBER working paper 10977.

[15] Heathcote, J., Storesletten K. and Violante G. L. (2004). The Macroeconomic Implications of Rising Wage Inequality in the U.S. mimeo, New York University.

[16] Hubbard, R. G., J. Skinner and S.P. Zeldes (1995). Precautionary Saving and Social Insurance. The Journal of Political Economy, Vol. 103, No. 2, pp. 360-399. 
[17] Huggett, M. (1993). The Risk-free Rate in Heterogeneous-agent Incomplete-insurance Economies. Journal of Economic Dynamics and Control, Vol. 17, No. 5-6, pp. 953-969.

[18] Imorohoroglu, A. (1992). The Welfare Cost of Inflation under Imperfect Insurance. Journal of Economic Dynamics and Control, Vol. 16, No. 1, pp. 79-91.

[19] Kennickell, A. B. (2003). A Rolling Tide: Changes in the Distribution of Wealth in the U.S., 1989-2001. working paper, Survey of Consumer Finances.

[20] Kotlikoff, L. J. (1989). Health Expenditures and Precautionary Savings. In What Determines Savings? Massachusetts, MIT Press.

[21] Krueger, D. and F. Perri (2005). Does Income Inequality Lead to Consumption Inequality? Evidence and Theory, Review of Economics Studies, Vol. 73, No. 1, pp. 163-193.

[22] Livshits, I., J. MacGee and M. Tertilt (2006). Consumer Bankruptcy: A Fresh Start. American Economic Review, forthcoming.

[23] Mendoza, E. G., A. Razin and L. L. Tesar (2005). Effective Tax Rates in Macroeconomics: Cross-country Estimates of Tax Rates on Factor Incomes and Consumption, Journal of Monetary Economics, Vol. 34, No. 3, pp. 297-323.

[24] Palumbo, Michael G. (1999). Uncertain Medical Expenses and Precautionary Saving Near the End of the Life Cycle, Review of Economic Studies, Vol. 66, No. 2, pp. 395-421.

[25] Rothschild, M. and J. Stiglitz. (1976). Equilibrium in Competitive Insurance Markets: An Essay on the Economics of Imperfect Information. Quarterly Journal of Economics, Vol. 90, No. 4, pp. 629-649.

[26] Sommers, J. P. (2002). Estimation of expenditures and enrollments for employer-sponsored health insurance. Agency for Healthcare Research and Quality, MEPS Methodology Report No. 14.

[27] Storesletten, K., C. Telmer and A. Yaron (2004). Cyclical Dynamics in Idiosyncratic LaborMarket Risk. The Journal of Political Economy, Vol. 112, No. 3, pp. 695-717.

[28] Tauchen, G. (1986). Finite State Markov-chain Approximations to Univariate and Vector Autoregressions. Economic Letters, Vol. 20, pp. 177-181

[29] Whitehouse, E. (2003). The Value of Pension Entitlements: A Model of Nine OECD Countries. OECD Social, Employment and Migration Working Papers No.9 
Table 1: Parameters of the model

\begin{tabular}{|c|c|c|}
\hline Parameter & "Description & Values \\
\hline \multicolumn{3}{|l|}{ Preferences } \\
\hline$\beta$ & discount factor & 0.94 \\
\hline$\sigma$ & relative risk aversion & 2.0 \\
\hline \multicolumn{3}{|c|}{ Technology and production } \\
\hline$\alpha$ & capital share & 0.33 \\
\hline$\delta$ & depreciation rate of capital & 0.06 \\
\hline \multicolumn{3}{|l|}{ Government } \\
\hline$\left\{a_{0}, a_{1}, a_{2}\right\}$ & income tax parameters (progressive part) & $\{0.258,0.768,0.650\}$ \\
\hline$\tau_{y}$ & income tax parameter (proportional part) & $4.367 \%$ \\
\hline $\bar{c}$ & social insurance minimum consumption & $11.23 \%$ of average labor income \\
\hline \multirow[t]{2}{*}{$\tau_{s s}$} & social security tax rate & $10.58 \%$ \\
\hline & Social security replacement ratio & $45 \%$ \\
\hline$q_{\text {med }}(x)$ & Medicare coverage ratio & see text \\
\hline$\tau_{\text {med }}$ & Medicare tax rate & $1.909 \%$ \\
\hline$p_{\text {med }}$ & Medicare premium & $2.11 \%$ of per capita output \\
\hline \multicolumn{3}{|c|}{ Demographics } \\
\hline$\rho_{o}$ & aging probability & $2.22 \%$ \\
\hline$\rho_{d}$ & death probability after retirement & $8.89 \%$ \\
\hline \multicolumn{3}{|c|}{ Individual health insurance } \\
\hline$q(x)$ & coverage ratio & see text \\
\hline$p$ & group insurance premium & $6.23 \%$ of average income $(\$ 1,870)$ \\
\hline$\psi$ & group insurance premium covered by a firm (\%) & $80 \%$ \\
\hline$\phi$ & premium mark-up (operational cost) & $9.45 \%$ \\
\hline
\end{tabular}


Figure 1: Take-up ratios over income $z$ (model and data)

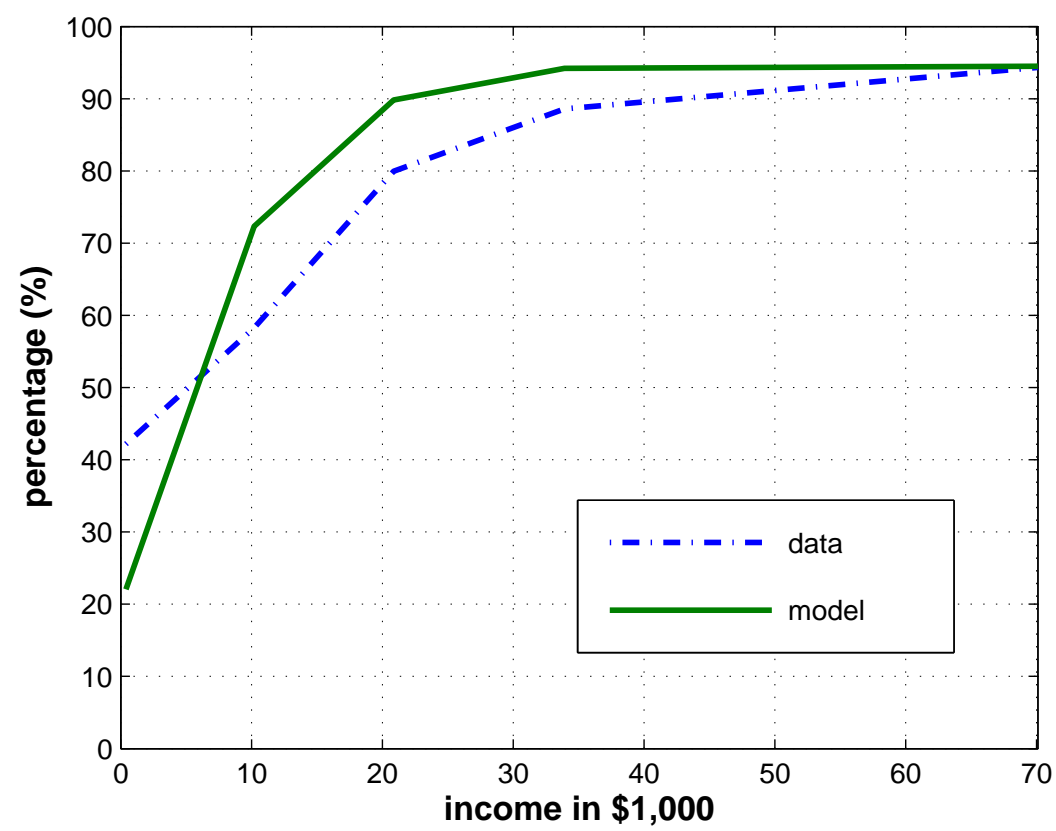


Figure 2: Take-up ratios over expenditures $x_{y}$ (model and data)

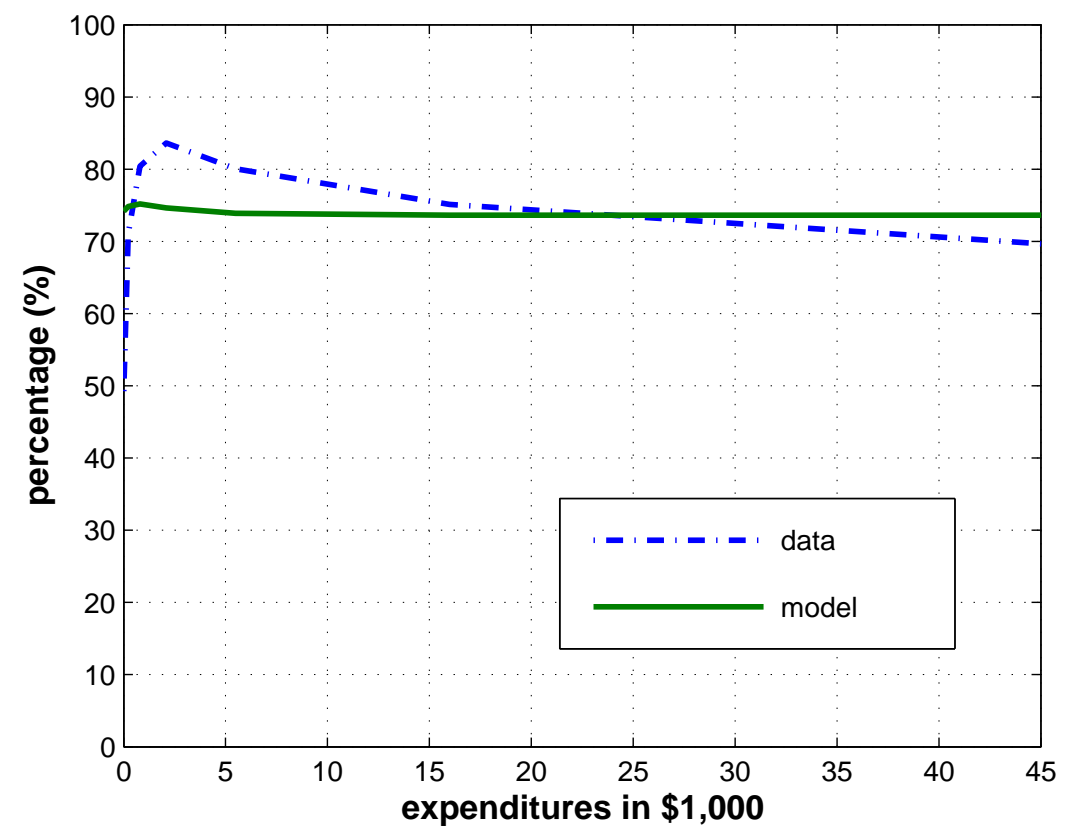


Table 2: Experiment 1: abolishing regressiveness of the deductibility of group insurance premium

\begin{tabular}{|l|c|c|c|}
\hline & Benchmark & $1-\mathrm{A}$ & $1-\mathrm{B}$ \\
\hline$p$ & $\$ 1,870$ & $\$ 2,887$ & $\$ 2,192$ \\
$T U R_{\text {all }}$ & $74.53 \%$ & $61.24 \%$ & $68.05 \%$ \\
$T U R_{n o G}$ & $42.04 \%$ & $44.82 \%$ & $42.63 \%$ \\
TUR $_{G}$ & $99.83 \%$ & $74.03 \%$ & $87.85 \%$ \\
Group & $99.83 \%$ & $55.83 \%$ & $82.21 \%$ \\
Individual & $0.00 \%$ & $18.20 \%$ & $5.64 \%$ \\
\hline Agg. output & 1.0000 & 1.0009 & 0.9997 \\
Agg. capital & 1.0000 & 1.0028 & 0.9991 \\
Agg. consumption & 1.0000 & 1.0011 & 0.9998 \\
Interest rate & $4.992 \%$ & $4.970 \%$ & $5.000 \%$ \\
Wage rate $(w)$ & 1.0000 & 1.0010 & 0.9997 \\
Offer cost $\left(c_{E}\right)$ & 1.0000 & 0.8633 & 0.9655 \\
Avg Labor Inc & 1.0000 & 1.0056 & 1.0006 \\
$\tau_{y}$ & $4.367 \%$ & $3.709 \%$ & $4.246 \%$ \\
$\tau_{s s}$ & $10.582 \%$ & $10.440 \%$ & $10.581 \%$ \\
$\tau_{m e d}$ Social ins. covered & $1.909 \%$ & $1.872 \%$ & $1.908 \%$ \\
\hline$C E V$ from transition & 1.0000 & 1.0010 & 1.0039 \\
all (young) & \multicolumn{3}{|l}{} \\
young w/ GHI offer & - & $-0.045 \%$ & $0.055 \%$ \\
young w/o GHI offer & - & $0.220 \%$ & $0.019 \%$ \\
\%w/CEV $>0$ (young) & - & $54.01 \%$ & $88.00 \%$ \\
\hline
\end{tabular}

\begin{tabular}{|l|l|l|l|}
\hline TUR by $z$ & $24.17 \%$ & $23.66 \%$ & $23.97 \%$ \\
$z_{1}$ & $68.06 \%$ & $68.51 \%$ & $68.53 \%$ \\
$z_{2}$ & $90.61 \%$ & $75.83 \%$ & $85.02 \%$ \\
$z_{3}$ & $95.02 \%$ & $72.14 \%$ & $82.89 \%$ \\
$z_{4}$ & $95.22 \%$ & $67.41 \%$ & $80.87 \%$ \\
$z_{5}$ & & & \\
\hline$T U R$ by $x$ & $74.18 \%$ & $49.87 \%$ & $56.74 \%$ \\
$x_{1}$ & $74.83 \%$ & $55.22 \%$ & $66.74 \%$ \\
$x_{2}$ & $75.19 \%$ & $63.48 \%$ & $72.03 \%$ \\
$x_{3}$ & $74.63 \%$ & $68.90 \%$ & $72.97 \%$ \\
$x_{4}$ & $73.90 \%$ & $70.87 \%$ & $73.71 \%$ \\
$x_{5}$ & $73.64 \%$ & $71.88 \%$ & $74.23 \%$ \\
$x_{6}$ & $73.64 \%$ & $73.35 \%$ & $75.92 \%$ \\
$x_{7}$ & & & \\
\hline
\end{tabular}

Aggregate output and capital and wage rate are normalized in terms of their benchmark levels. 1-A: abolish group insurance deductibility from income and payroll tax bases

1-B: abolish group insurance deductibility from income tax base and provide credit for group insurance at the average income tax rate 
Table 3: Experiment 2: extending tax deductibility or subsidy to the non-group insurance market

\begin{tabular}{|c|c|c|c|c|}
\hline & Benchmark & $2-\mathrm{A}$ & $2-\mathrm{B}$ & $2-\mathrm{C}$ \\
\hline$p$ & $\$ 1,870$ & $\$ 2,349$ & $\$ 1,867$ & $\$ 1,867$ \\
\hline$T U R_{\text {all }}$ & $74.53 \%$ & $89.07 \%$ & $95.19 \%$ & $91.65 \%$ \\
\hline$T U R_{n o G}$ & $42.04 \%$ & $75.25 \%$ & $89.23 \%$ & $81.13 \%$ \\
\hline$T U R_{G}$ & $99.83 \%$ & $99.83 \%$ & $99.84 \%$ & $99.84 \%$ \\
\hline Group & $99.83 \%$ & $75.59 \%$ & $99.84 \%$ & $99.84 \%$ \\
\hline Individual & $0.00 \%$ & $24.24 \%$ & $0.00 \%$ & $0.00 \%$ \\
\hline Agg. output & 1.0000 & 0.9968 & 0.9926 & 0.9927 \\
\hline Agg. capital & 1.0000 & 0.9903 & 0.9779 & 0.9781 \\
\hline Agg. consumption & 1.0000 & 0.9958 & 0.9924 & 0.9924 \\
\hline Interest rate & $4.992 \%$ & $5.064 \%$ & $5.158 \%$ & $5.156 \%$ \\
\hline Wage rate $(w)$ & 1.0000 & 0.9968 & 0.9927 & 0.9927 \\
\hline Offer cost $\left(c_{E}\right)$ & 1.0000 & 0.9514 & 0.9987 & 0.9987 \\
\hline Avg Labor Inc & 1.0000 & 0.9873 & 0.9924 & 0.9925 \\
\hline$\tau_{y}$ & $4.367 \%$ & $4.675 \%$ & $5.176 \%$ & $5.002 \%$ \\
\hline$\tau_{s s}$ & $10.582 \%$ & $10.682 \%$ & $10.581 \%$ & $10.581 \%$ \\
\hline$\tau_{\text {med }}$ & $1.909 \%$ & $1.934 \%$ & $1.928 \%$ & $1.928 \%$ \\
\hline Social ins. covered & 1.0000 & 0.9840 & 0.9522 & 0.9552 \\
\hline$C E V$ from transition & & & & \\
\hline all (young) & - & $0.436 \%$ & $1.107 \%$ & $1.074 \%$ \\
\hline young w/ GHI offer & - & $0.199 \%$ & $0.512 \%$ & $0.564 \%$ \\
\hline young w/o GHI offer & - & $0.741 \%$ & $1.871 \%$ & $1.729 \%$ \\
\hline$\% w / C E V>0$ (young) & - & $98.53 \%$ & $99.96 \%$ & $99.96 \%$ \\
\hline
\end{tabular}

\begin{tabular}{|l|l|l|l|l|}
\hline TUR by $z$ & $24.17 \%$ & $52.60 \%$ & $78.96 \%$ & $78.84 \%$ \\
$z_{1}$ & $68.06 \%$ & $93.73 \%$ & $97.53 \%$ & $96.57 \%$ \\
$z_{2}$ & $90.61 \%$ & $99.82 \%$ & $99.83 \%$ & $92.28 \%$ \\
$z_{3}$ & $95.02 \%$ & $99.98 \%$ & $99.98 \%$ & $95.17 \%$ \\
$z_{4}$ & $95.22 \%$ & $99.99 \%$ & $99.99 \%$ & $95.58 \%$ \\
$z_{5}$ TUR by $x$ & $74.18 \%$ & $89.75 \%$ & $98.65 \%$ & $95.32 \%$ \\
$x_{1}$ & $74.83 \%$ & $89.58 \%$ & $96.99 \%$ & $93.48 \%$ \\
$x_{2}$ & $75.19 \%$ & $89.13 \%$ & $94.93 \%$ & $91.30 \%$ \\
$x_{3}$ & $74.63 \%$ & $88.65 \%$ & $93.26 \%$ & $89.52 \%$ \\
$x_{4}$ & $73.90 \%$ & $88.21 \%$ & $91.66 \%$ & $88.01 \%$ \\
$x_{5}$ & $73.64 \%$ & $87.71 \%$ & $90.56 \%$ & $87.29 \%$ \\
$x_{6}$ & $73.64 \%$ & $87.32 \%$ & $89.82 \%$ & $86.86 \%$ \\
$x_{7}$ & \multicolumn{3}{|c}{} \\
\hline
\end{tabular}

Aggregate output and capital and wage rate are normalized in terms of their benchmark levels. 2-A: extend the same deduction for the purchase of individual insurance

2-B: provide credit of $\$ 1,000$ for the purchase of individual insurance if no access to group insurance

2-C: same as 2-B but the subsidy is subject to annual income $<\$ 30,000$ 


\section{Appendix}

\section{A Transition matrices for $x_{y}, x_{o}, z$ and $i_{E}$ :}

The age-specific transition matrices for the health expenditures shocks $x_{y}$ for young and $x_{o}$ for old are given as follows.

$$
\begin{aligned}
\Pi_{x_{y}}= & {\left[\begin{array}{lllllll}
0.580 & 0.238 & 0.095 & 0.058 & 0.022 & 0.007 & 0.001 \\
0.252 & 0.340 & 0.239 & 0.107 & 0.049 & 0.010 & 0.003 \\
0.107 & 0.225 & 0.315 & 0.229 & 0.093 & 0.022 & 0.008 \\
0.052 & 0.112 & 0.227 & 0.360 & 0.205 & 0.037 & 0.008 \\
0.032 & 0.069 & 0.134 & 0.268 & 0.388 & 0.094 & 0.015 \\
0.030 & 0.060 & 0.086 & 0.184 & 0.383 & 0.198 & 0.059 \\
0.008 & 0.016 & 0.104 & 0.143 & 0.278 & 0.300 & 0.152
\end{array}\right] } \\
\Pi_{x_{o}}= & {\left[\begin{array}{lllllll}
0.658 & 0.175 & 0.077 & 0.047 & 0.036 & 0.004 & 0.003 \\
0.199 & 0.373 & 0.194 & 0.137 & 0.076 & 0.018 & 0.005 \\
0.063 & 0.233 & 0.297 & 0.242 & 0.130 & 0.027 & 0.008 \\
0.050 & 0.130 & 0.279 & 0.280 & 0.210 & 0.040 & 0.011 \\
0.027 & 0.096 & 0.176 & 0.320 & 0.284 & 0.081 & 0.016 \\
0.028 & 0.089 & 0.090 & 0.232 & 0.322 & 0.186 & 0.053 \\
0.059 & 0.012 & 0.113 & 0.128 & 0.379 & 0.242 & 0.067
\end{array}\right] }
\end{aligned}
$$

The age-specific transition matrices for the income $z$ and group insurance offer status $i_{E}$ are given as follows. Entries 1 to 5 from the top are the income bins 1 to 5 with employer-based insurance and entries 6 to 10 are the five income groups without insurance offered. ${ }^{16}$

$$
\Pi_{Z, E}=\left[\begin{array}{ccccc|ccccc}
0.027 & 0.316 & 0.215 & 0.124 & 0.100 & 0.135 & 0.047 & 0.033 & 0.000 & 0.004 \\
0.015 & 0.383 & 0.261 & 0.089 & 0.043 & 0.070 & 0.098 & 0.035 & 0.003 & 0.003 \\
0.005 & 0.142 & 0.506 & 0.212 & 0.066 & 0.017 & 0.033 & 0.013 & 0.005 & 0.000 \\
0.005 & 0.044 & 0.168 & 0.593 & 0.170 & 0.009 & 0.006 & 0.004 & 0.000 & 0.000 \\
0.005 & 0.022 & 0.035 & 0.135 & 0.777 & 0.015 & 0.005 & 0.006 & 0.000 & 0.000 \\
\hline 0.008 & 0.023 & 0.010 & 0.004 & 0.002 & 0.772 & 0.131 & 0.031 & 0.010 & 0.009 \\
0.004 & 0.059 & 0.022 & 0.024 & 0.002 & 0.186 & 0.467 & 0.159 & 0.052 & 0.027 \\
0.001 & 0.025 & 0.051 & 0.030 & 0.005 & 0.091 & 0.264 & 0.346 & 0.127 & 0.062 \\
0.003 & 0.010 & 0.032 & 0.036 & 0.016 & 0.081 & 0.185 & 0.187 & 0.334 & 0.115 \\
0.005 & 0.000 & 0.007 & 0.011 & 0.021 & 0.080 & 0.102 & 0.122 & 0.169 & 0.484
\end{array}\right]
$$

\section{B Calibration of the health insurance coverage ratio $q(x)$}

We use a polynomial of the following form:

$$
q(x)=\beta_{0}+\beta_{1} \log x+\beta_{2}(\log x)^{2},
$$

\footnotetext{
${ }^{16}$ For example, $\Pi_{Z, E}(7,3)=0.022$ implies that given the agent has income $z=2$ and no group insurance offer this period, the probability of having income $z=3$ and a group insurance offer in the next period is $2.2 \%$, conditional on not aging tomorrow.
} 
where $x$ is the health expenditures in US dollars. We estimate the coefficients so that the function fits the data best for the range of expenditures used in the model. We obtain $\beta_{0}=0.2540$, $\beta_{1}=0.0397$ and $\beta_{2}=0.0013$. Applying the function $q(x)$ to the expenditure grids for each generation, the coverage ratio for each grid point is given as follows.

\begin{tabular}{cccccccc} 
bin & 1 & 2 & 3 & 4 & 5 & 6 & 7 \\
\hline$q(x)$ & 0.250 & 0.507 & 0.578 & 0.634 & 0.693 & 0.762 & 0.832
\end{tabular}

